\title{
USING ARTIFICIAL INTELLIGENCE TO FORECAST MONTHLY RAINFALL UNDER PRESENT AND FUTURE CLIMATES FOR THE BOWEN BASIN, QUEENSLAND, AUSTRALIA
}

\author{
J. ABBOT \& J. MAROHASY \\ School of Medical and Applied Science, Central Queensland University, Noosa, Queensland, Australia.
}

\begin{abstract}
There is a need for more skilful medium-term rainfall forecasts for the Bowen Basin, a key coal-mining region in Queensland, Australia. Prolonged heavy rainfall during the 2010-2011 summer was not forecasted and it severely affected industry operations. Official forecasts are currently based on general circulation models (GCMs) and indicate there will be change in the timing and strength of the rainfall in the Bowen Basin with climate change.

A more skilful medium-term rainfall forecast for the present climate can be achieved through the use of artificial neural networks (ANNs). ANN can be used to generate monthly forecasts 3 months in advance. These forecasts can be improved through a weighted linear combination of forecasts. Principal component analysis prior to inputting data does not improve the forecast. An ANN can provide an independent method of GCM validation under future climates with results in reasonable agreement with the averaged values from the GCM ensembles: suggesting a decline in summer rainfall and an increase in winter rainfall at Nebo, a locality in the Bowen Basin, under the $3^{\circ} \mathrm{C}$ warmer scenario. This represents a smoothing of the annual variability in rainfall for the locality of Nebo rather than more climatic extremes with global warming.

Keywords: Rainfall, artificial neural network, climate change, model independence.
\end{abstract}

\section{INTRODUCTION}

The Bowen Basin in Queensland contains the largest coal reserves in Australia. The very wet summer of 2010-2011 severely affected mining operations. It is estimated that $85 \%$ of Queensland coal mines had to either restrict production or close entirely [1, 2]. By May 2011, Queensland's coal mining sector had recovered to only $75 \%$ of its pre-flood output with a loss of A $\$ 5.7$ billion, equivalent to $2.2 \%$ of Queensland's gross state product for the financial year ending June 2011. A report prepared for Australia's National Climate Change Adaptation Research Facility examined the impacts of the extreme weather event. It concluded that currently available climate forecasts are not useful enough to the industry, lacking localized information, and other micro details, to enable focused pro-active planning and risk management [2].

Official seasonal rainfall forecasts from the Australian Bureau of Meteorology (BOM) have historically been issued based on output from a relatively simple statistical model using climate indices, in particular, patterns in sea surface temperatures (Fig. 1). In winter 2013, the BOM transferred to a system based on the Predictive Ocean Atmosphere Model for Australia (POAMA). POAMA is a general circulation model (GCM), which has been producing forecasts since 2001. However, despite substantial research efforts and technological advances, there is no evidence to suggest that POAMA, or other GCMs, can consistently produce a more skilful medium-term rainfall forecast than the simple statistical models historically used to predict seasonal rainfall using climate indices [3-5].

Both the official statistical models used until winter 2013, and POAMA, provide the seasonal forecast as a conditional probability of rainfall being greater than or less than a seasonal median for the 3-month period of the designated season. For example, the statistical forecast issued in 


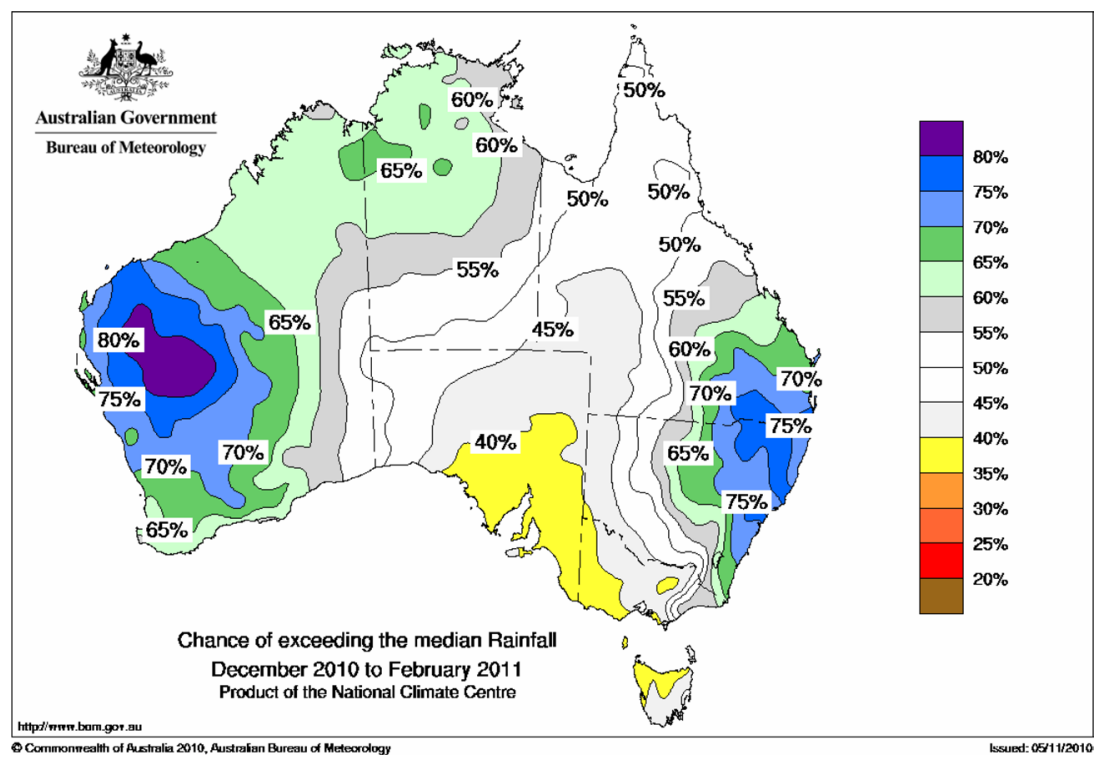

Figure 1: Seasonal rainfall forecast issued in November 2010 by the Australian Bureau of Meteorology.

November 2010 by the BOM for summer (December 2010, January 2011 and February 2011) was in the form of a seasonal forecast map (Fig. 1), indicating a 50\%-55\% probability of above median rainfall for the Bowen Basin, but with no indication of the magnitude and distribution of rainfall within this 3-month period.

Artificial neural networks (ANNs) are not routinely used by government agencies in Australia to generate seasonal rainfall forecasts but have been used in other parts of the world, particularly in regions subject to highly variable monsoonal rainfall, reviewed in Abbot and Marohasy [6]. They are massive parallel-distributed, information-processing systems with characteristics resembling the biological neural networks of the human brain. In essence, they mine data for historical patterns that can then be applied to predict future events. The application of this approach requires sufficient relevant historical data, the presence of patterns that can be detected and their continuance into the future period where forecasts are desired. From this perspective, the ANN approach does not differ from other statistical models, but is much more adaptable in recognizing and utilizing complex patterns.

The first part of this study examines the application of ANNs for forecasting monthly rainfall 1 month in advance for the site of Nebo, a town located close to a major open pit coal mine operated by Rio Tinto at Hail Creek in the Bowen Basin. It builds on a paper presented at the 7th International Conference on Sustainable Water Resource Management [7]. In particular, we investigate the potential to generate forecast signals corresponding to periods of very heavy rainfall, with a lead-time that would potentially alert mine operators of impending flood risks. We then seek to improve the ANN forecast through the use of a weighted linear combination of forecasts and PCA. In the second part of this study, output from an ANN under climate change is compared with the results from investigations using GCMs. 


\section{DATA AND METHODS}

\subsection{Historical data}

ANN models, like the simple statistical models until recently used to produce seasonal rainfall forecasts by the BOM, use historical rainfall data and climate indices. The site of Nebo was chosen because of its proximity to a coal mine in the Bowen Basin and because it is a site with over 120 years of historical rainfall data. Input variables used in this study included Niño 3.4 and the Southern Oscillation Index (SOI) that represent the El Niño-Southern Oscillation (ENSO), which is thought to be a main driver of Queensland rainfall [8]. In addition, the Inter-decadal Pacific Oscillation (IPO), was used, which is thought to modulate the influence of ENSO on rainfall along the Australian east coast [9-11].

The monthly rainfall data for Nebo (station 033054) were obtained from the BOM. Atmospheric temperature data, both maxima and minima, were obtained from the BOM for the Te Kowai Experimental Station in Mackay (station 033047) available from the year 1908. The values for SOI were also sourced from the BOM. The values for the climate index Niño 3.4 were sourced from the Royal Netherlands Meteorological Institute Climate Explorer - a web application that is part of the World Meteorological Organisation and European Climate Assessment and Dataset project. The values for IPO were provided by Chris Folland from the UK Met Office Hadley Centre.

\subsection{Principal component analysis}

Rainfall can be regarded as an integration of stochastic and deterministic components of a signal [12]. In theory, once the stochastic component, which is considered a type of noise, is appropriately eliminated, the deterministic component can then be more easily modelled. For the purpose of removing this noise, many data pre-processing techniques, including principal component analysis (PCA) [12, 13], wavelet analysis [13, 14] and singular spectrum analysis [12, 15] can be applied.

In this study, we applied PCA to the input data. The results in Table 1 show that higher root mean square error (RMSE) values and lower correlation coefficients were obtained for rainfall forecasts using PCA indicating PCA did not improve the forecast. This is consistent with the results reported by Wu et al. [12], and may reflect the variable nature of the Nebo rainfall data. Further investigations with other signal pre-processing techniques will be undertaken in future studies of the application of ANNs to Queensland rainfall.

\subsection{Artificial neural networks}

ANN software, NeuroSolutions 6 for Excel (NeuroDimensions, FL, USA), was used with an Elman neural network. The desired output, which is the observed rainfall, was assigned as the monthly rainfall with a lead-time of 1 month ahead of the current month. For each input data set, the ANN was optimized for 3000 epochs using a genetic optimization algorithm for 10 or 20 generations. Training sets comprised approximately $85 \%$ of the total data with the remaining $15 \%$ used for testing. The test period, which is also the forecast period, was initially set for 137 months from August 2000 to December 2011 that included the exceptionally wet summer of 2010-2011.

Six unary input data sets were constructed corresponding to monthly values of rainfall (Rain), SOI, IPO, Niño 3.4 (Niño), maximum atmospheric temperature (MaxT) and minimum atmospheric temperature (MinT). Each unary data set comprised the current monthly value, plus 12 lagged values 
Table 1: Principal component analysis did not improve the skill of the forecast.

\begin{tabular}{lccccc}
\hline & \multicolumn{2}{c}{ RMSE pre-processing } & & \multicolumn{2}{c}{$\begin{array}{c}\text { Correlation coefficient } \\
\text { pre-processing }\end{array}$} \\
\cline { 2 - 3 } \cline { 6 - 7 } Input data sets & None & PCA & & None & PCA \\
\hline Rain & 67.9 & 72.9 & & 0.433 & 0.429 \\
Max Temp/IPO & 63.7 & 69.8 & & 0.591 & 0.506 \\
SOI/MaxT & 63.7 & 67.7 & & 0.627 & 0.544 \\
SOI/Nino/MinT & 63.4 & 68.9 & & 0.630 & 0.529 \\
Rain/MinT/SOI & 60.2 & 73.9 & & 0.675 & 0.548 \\
MaxT/MinT/SOI & 61.9 & 67.7 & & 0.619 & 0.550 \\
Rain/Nino/IPO/MinT/MaxT & 54.4 & 69.2 & & 0.737 & 0.523 \\
IPO/MinT & 64.8 & 69.4 & & 0.617 & 0.510 \\
\hline
\end{tabular}

Table 2: Combinations of input variables tested in the neural network.

\begin{tabular}{lcclc}
\hline $\begin{array}{l}\text { Input data } \\
\text { sets }\end{array}$ & $\begin{array}{c}\text { Number of } \\
\text { combinations }\end{array}$ & $\begin{array}{c}\text { Range of } \\
\text { RMSE }(\mathrm{mm})\end{array}$ & \multicolumn{2}{c}{$\begin{array}{c}\text { Combinations giving lowest } \\
\text { RMSE values (mm) }\end{array}$} \\
\hline Unary & 6 & $81.6-67.9$ & Rain & 67.9 \\
Binary & 15 & $91.0-63.7$ & MaxT + IPO & 63.7 \\
Ternary & 20 & $76.0-60.2$ & Rain + MinT + SOI & 60.2 \\
& & & Max + MinT + SOI & 61.9 \\
Quaternary & 15 & $71.4-64.0$ & SOI + Nino + MinT & 63.4 \\
Quinary & 6 & Rain + MinT + SOI & 64.0 \\
Total & $62.4-55.4$ & Rain + MaxT + MinT + & 55.4 \\
& 6 & & IPO + Nino \\
\end{tabular}

for the previous 12 months. Binary and ternary combinations of these unary sets were also used as inputs (Table 2). A total of 62 combinations were tested (Table 2).

RMSE gives a simple, transparent quantitative measure of the difference between the forecast rainfall and observed rainfall for the unary, binary, ternary, quaternary and quinary inputs (Table 1). The lower the RMSE, the smaller the difference between the forecast and the observed rainfall and therefore the more skilful the forecast. The specific combination that gave the lowest RMSE was Rain with IPO, Niño 3.4 and maximum and minimum temperatures (Table 1).

\subsection{Future climates}

Over the past two decades, there has been considerable interest worldwide in forecasting climatic change, particularly in the context of increasing levels of atmospheric carbon dioxide. The vast majority of these forecasts, particularly for temperatures and rainfall, have been produced using GCMs, 
which represent a very different technology to ANNs. Irving et al. [16] assess the output from 27 GCMs that will be used in the development of the Working Group II report of the Intergovernmental Panel on Climate Changes' Fifth Assessment Report, AR5 [17], to determine climate change projections for a region referred to as Queensland Interior (QIN), which includes Nebo in the Bowen Basin.

ANN models can be used to forecast future climates. In essence, the ANN produces its forecast by relating a set of input values, including minimum and maximum atmospheric temperatures at a specific location, to rainfall. Having trained the ANN, it is then also possible to substitute the different sets of input temperature values to answer the question: how would rainfall vary in response to specified increased or decreased atmospheric temperatures? The first ANN model developed in this study trained with the quaternary input set (IPO + SOI + maximum + minimum temperature) was used where maximum and minimum temperatures were incrementally increased and decreased in tandem by $1^{\circ} \mathrm{C}$, up to $3^{\circ} \mathrm{C}$, to forecast the effect of climate change on rainfall at Nebo.

\section{RESULTS AND DISCUSSION}

\subsection{Forecasting rainfall for Nebo using an ANN}

The ANN models represent a leap forward in computational versatility. The ANN approach has the advantage that it enables input of a large number of variables simultaneously, with no assumptions as to which may be most significant in the prediction of rainfall for a specific lead period. If particular columns of inputs within an input set, or an entire unary set, are not useful for prediction, there is a high probability that these will be preferentially culled by the genetic algorithm, thus progressively refining the model by retaining only more significant inputs.

A quinary combination of rainfall, maximum and minimum temperatures, IPO and Niño 3.4 gave the most skilled forecast (Table 2). This represents the forecast with lowest value of RMSE for the 62 examples tested (Table 2). Sensitivity analysis suggests that the inputs important to the model are not intuitively obvious. For example, lagged values to 10 and 11 months for minimum temperature were important in achieving the low RMSE of $55.4 \mathrm{~mm}$.

Combing forecast results for rainfall and temperatures from different models is common in climate science particularly in association with output from GCMs [18-20]. As with GCMs, it is possible to achieve superior rainfall forecasts through combining output from individual ANN models. A linear combination of the outputs shown from the ternary input data set (Rain + MinT + SOI) and the quinary input set (Rain + MaxT + MinT + Niño + IPO) gave the forecast with the lowest RMSE. The outputs were combined in the ratio of $0.7: 1.3$ and then the result divided by a factor of 2 . The RMSE of $54.7 \mathrm{~mm}$ for the combination is lower than for either of the individual outputs (Table 2).

This output when charted (Fig. 2) provides significantly more useful information for a specific location than the seasonal forecast from the BOM issued in November 2010 (Fig. 1).

The ANN model did forecast the exceptionally wet summer of 2010-2011 (Fig. 2). The ANN model was broadly able to differentiate between the recent wet summer months, relative to the dryer summer months during the extended drought (Fig. 2). The ANN model did not, however, forecast the wetter summer in 2003-2004, 2006-2007 or 2009-2010 (Fig. 2).

\subsection{Future climate}

Because of the elevated levels of atmospheric carbon dioxide from the burning of fossil fuels, it is expected that the climate will change in the future. It is unclear, however, whether this will mean an increase or decrease in rainfall for the Bowen Basin as different GCMs produce widely divergent 


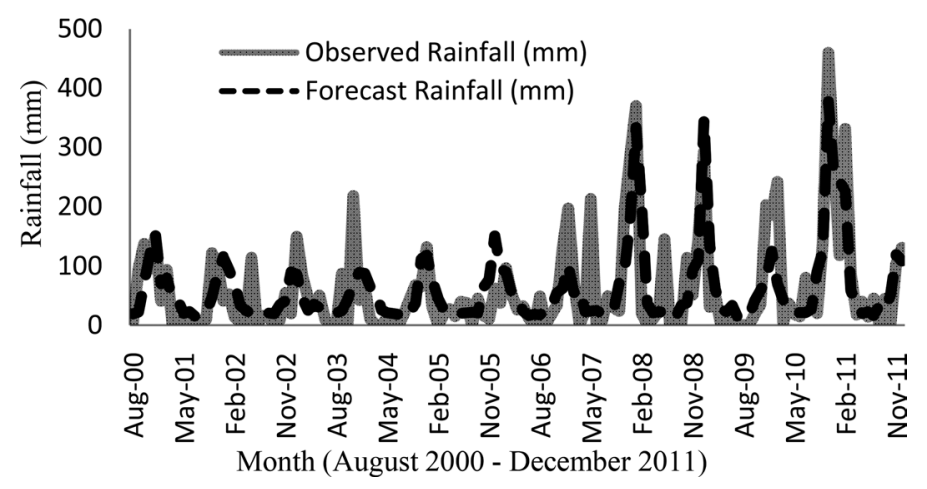

Figure 2: Monthly rainfall forecast with 1-month lead time generated by combining two forecasts and post-processing (RMSE $54.7 \mathrm{~mm}, r=0.74$ ).

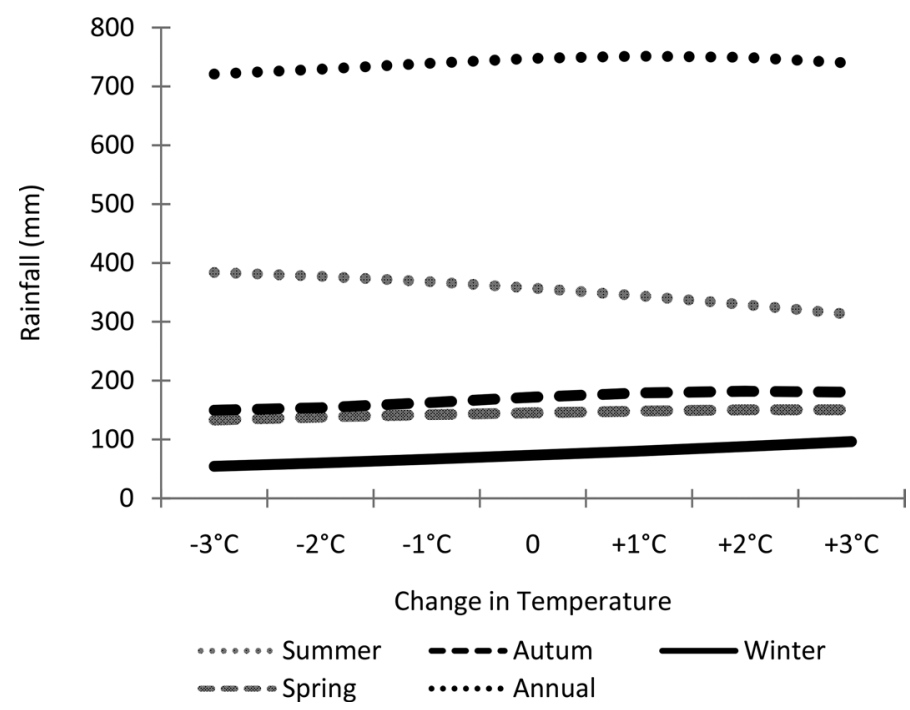

Figure 3: Projected change in annual and seasonal rainfall for a $\pm 3^{\circ} \mathrm{C}$ change in temperature.

results $[16,19]$. It was hoped that with advances in climate modelling and computing power, the divergence would reduce. However, the opposite has been the case, with more divergence amongst the 27 models already assessed as part of the World Climate Research Programme 5, CMIP5, than existed between the models used as part of CMIP3 that formed the basis of the IPCC's Fourth Assessment Report, AR4 [16]. There are inherent problems common to many GCMs [21-24], and it remains unclear whether those biases affect the projections of future climate in a persistent way.

Given these issues, particularly the lack of model independence [21], it seems particularly relevant to benchmark forecasts of future climate against an independent method and independent model.

For a $3^{\circ} \mathrm{C}$ increase in temperature, the annual forecast change from the ANN is small, a decline in rainfall from 747 to $739 \mathrm{~mm}$ (Fig. 3). There are, however, more pronounced seasonal changes in rainfall with the summer wet-season rainfall declining over the $6^{\circ} \mathrm{C}$ range, from 383.7 to $312 \mathrm{~mm}$ 
Table 3: Projected percentage change in annual and seasonal rainfall from ANN model compared with output from GCMs after Irving et al. [16].

\begin{tabular}{lccccc}
\hline $\begin{array}{l}\text { Temperature } \\
\text { change }\left({ }^{\circ} \mathrm{C}\right)\end{array}$ & $\begin{array}{c}\text { Summer } \\
(\mathrm{DJF}, \%)\end{array}$ & $\begin{array}{c}\text { Autumn } \\
(\mathrm{MAM}, \%)\end{array}$ & $\begin{array}{c}\text { Winter } \\
(\mathrm{JJA}, \%)\end{array}$ & $\begin{array}{c}\text { Spring } \\
(\mathrm{SON}, \%)\end{array}$ & Annual (\%) \\
\hline \multicolumn{5}{l}{ ANN forecast change as percentage change relative to present } \\
-3 & +7.4 & -12.9 & -25.8 & -8.3 & -3.6 \\
-2 & +5.6 & -10.4 & -18.1 & -5.0 & -2.5 \\
-1 & +3.1 & -5.5 & -9.5 & -2.2 & -1.1 \\
+1 & -3.7 & +4.2 & +9.4 & +2.0 & +0.5 \\
+2 & -7.8 & +5.9 & +20.2 & +3.4 & +0.3 \\
+3 & -12.5 & +5.0 & +31.7 & +3.4 & -1.1 \\
\hline
\end{tabular}

GCM forecast change as percentage relative to present (from Irving et al. [16])

Region designated as Tropical North Australia (TNA)

\begin{tabular}{|c|c|c|c|c|c|}
\hline$+2.5 \pm 0.5$ & $-4.3 \pm 21.6$ & $-6.8 \pm 24.1$ & $+4.2 \pm 76.1$ & $-4.0 \pm 56.8$ & $-4.9 \pm 21.2$ \\
\hline \multicolumn{6}{|c|}{ Region designated as Queensland Interior (QIN) } \\
\hline$+2.5 \pm 0.5$ & $+0.7 \pm 19.0$ & $-8.8 \pm 31.9$ & $+17.3 \pm 39.1$ & $-10.7 \pm 29.6$ & $-4.9 \pm 20.8$ \\
\hline
\end{tabular}

(Fig. 3). This represents a decrease in $12.5 \%$ over the present climate's summer rainfall (Table 3 ). There is a $31.7 \%$ forecast increase in winter rainfall over present climate (Table 3), but this represents a smaller total change because most rain falls in the summer wet season at Nebo (Fig. 3).

The annual and seasonal forecasts from the ANN model under different temperature regimes representing hypothetical future climates broadly accord with the average computed from output from 27 GCMs [16] (Table 3).

Nebo has a climate most similar to the region designated as TNA, Tropical Northern Australia, with a pronounced summer monsoon, but is placed within a zone designated by the World Climate Research Programme as QIN, Queensland Interior. Forecasts averaged from GCM ensembles for TNA under a $+2.5 \pm 0.5^{\circ} \mathrm{C}$ climate show an increase in winter rainfall and a decrease in summer rainfall but with large variability about this mean (Table 3 ). The region designated QIN also shows an increase in winter rainfall under global warming but almost no change in summer rainfall $+0.7^{\circ} \mathrm{C}$ (Table 3).

The GCM output in Table 3 represents an average of more than two-dozen ensembles comprising individual forecasts that represent a broad spectrum of highly divergent rainfall scenarios [16]. With the wide range of forecast results for GCM ensembles, it is not surprising that some individual GCM models produce conclusions contrasting with the ensemble averages. For example, research commissioned by the Queensland Government [25] that considered a doubling of atmospheric carbon dioxide concentration and the resulting impact on rainfall was simulated by the GCM HiGEM and forecast an increase in Queensland's annual rainfall of about $10 \%$, with a more compressed and intense wet season while the remainder of the year was drier [25]. This result is more consistent with the popular representation of global warming as creating climatic extremes but is not supported by output from the ANN model (Fig. 4 and Table 3). The changed seasonal rainfall pattern with global warming as forecast by the ANN for Nebo would have the effect of smoothing the annual variability in rainfall (Fig. 4). 


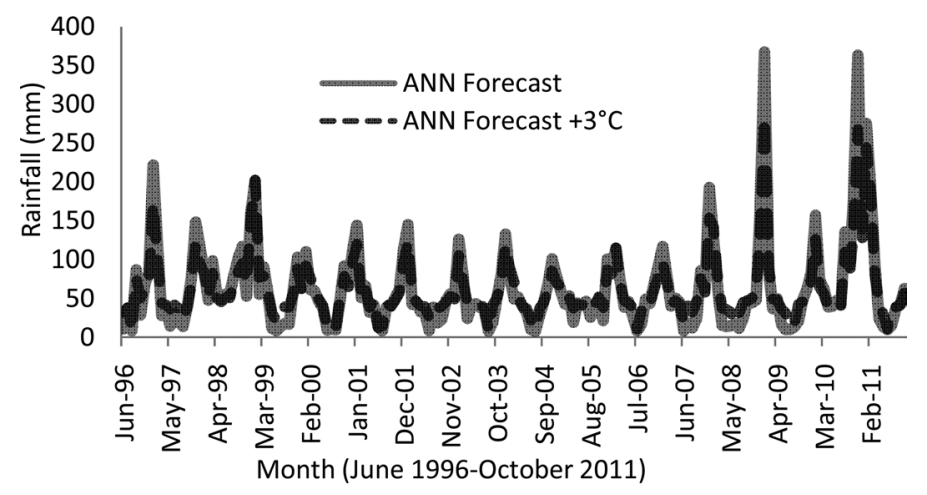

Figure 4: Monthly rainfall forecast with $3^{\circ} \mathrm{C}$ increase in atmospheric temperature produced by neural network.

\section{CONCLUSIONS}

Since June 2013, the BOM official rainfall forecasts for the Bowen Basin have been based on output from the GCM POAMA while acknowledging that the skill level is generally low [3, 5, 22, 23]. Nevertheless, the investment in GCMs for medium and also long-term rainfall continues to increase with a belief that forecast skill will improve with advances in climate modelling and computing power [16]. This has not proven to be the case over the last two decades, and just adding more GCMs that lack independence may compound the problem if the objective is a more skilful rainfall forecast [21].

Until recently, the BOM issued medium-term rainfall predictions as seasonal forecasts based on statistical models $[4,26]$ that used anomalies in sea surface temperatures as input. More sophisticated statistical models, in particular, ANN, are perhaps a way forward [5-7] and, as demonstrated in this paper, can already provide a more skilful monthly rainfall forecast for the coal mining industry in the Bowen Basin. There is also potential to improve the forecast through pre-processing of inputs to the ANN, though so far PCA has not proven useful.

ANNs can also be used to benchmark future climate forecasts for the Bowen Basin made by GCMs. Results from our ANN are broadly consistent with the averaged output from 27 GCM ensembles and indicate that global warming would have the effect of reducing the current annual variability in rainfall in the Bowen Basin (Fig. 4 and Table 3).

\section{ACKNOWLEDGEMENT}

This work was funded by the B. Macfie Family Foundation.

\section{REFERENCES}

[1] Queensland Government Flood Commission of Inquiry. Chapter 13 Mining 2012, http://www. floodcommission.qld.gov.au/publications/final-report

[2] Sharma, V., van de Graaff, S., Loechel, B. \& Franks, D., Extractive Resource Development in a Changing Climate: Learning the Lessons from Extreme Weather Events in Queensland, Australia. National Climate Change Adaptation Research Facility: Gold Coast, p. 110, 2013.

[3] Schepen, A., Wang, Q. \& Robertson J., Evidence for using lagged climate indices to forecast Australian seasonal rain. Journal of Climate, 25(4), pp. 1230-1246, 2012. doi: http://dx.doi. org/10.1175/jcli-d-11-00156.1 
[4] Fawcett, R.J.B. \& Stone, R.J., A comparison of two seasonal rainfall forecasting systems for Australia. Australian Meteorological and Oceanographic Journal, 60, pp. 15-24, 2010.

[5] Abbot, J. \& Marohasy, J., Input selection and optimisation for monthly rainfall forecasting in Queensland, Australia, using artificial neural networks. Atmospheric Research, 138, pp. 166-178, 2014. doi: http://dx.doi.org/10.1016/j.atmosres.2013.11.002

[6] Abbot, J. \& Marohasy, J., Application of artificial neural networks to rain forecasting in Queensland, Australia. Advances in Atmospheric Sciences, 29(4), pp. 717-730, 2012. doi: http://dx.doi.org/10.1007/s00376-012-1259-9

[7] Abbot, J. \& Marohasy, J., The potential benefits of using artificial intelligence for monthly rainfall forecasting for the Bowen Basin, Queensland, Australia. WIT Transactions on Ecology and the Environment, Vol. 171, (C) 2013 WIT Press: Southampton, www.witpress.com, ISSN 1743-3541 (on-line), doi:10.2495/WRM130261.

[8] Risbey, J.S., Pook, M.J. \& Mcintosh, P.C., On the remote drivers of rain variability in Australia. Monthly Weather Review, 137, pp. 3233-3253, 2009. doi: http://dx.doi. org/10.1175/2009mwr2861.1

[9] Verdon, D.C. \& Franks, S.W., Long-term behavior of ENSO: interactions with the PDO over the past 400 years inferred from paleoclimate records. Geophysical Research Letters, 33(6), L06712, 2006. doi: http://dx.doi.org/10.1029/2005gl025052

[10] Power, S., Casey, T., Folland, C., Colman, A. \& Mehta, V., Interdecadal modulation of the impact of ENSO on Australia. Climate Dynamics, 15, pp. 319-324, 1999. doi: http://dx.doi. org/10.1007/s003820050284

[11] Cai, W. \& van Rensch, P., The 2011 southeast Queensland extreme summer rain: a confirmation of a negative Pacific Decadal Oscillation phase? Geophysical Research Letter, (39), p. L08702, 2012. doi: http://dx.doi.org/10.1029/2011gl050820

[12] Wu, C.L., Chau, K.W. \& Fan, C., Prediction of rainfall time series using modular artificial neural networks coupled with data-preprocessing techniques. Journal of Hydrology, 389, pp. 146167, 2010. doi: http://dx.doi.org/10.1016/j.jhydrol.2010.05.040

[13] Camberlin, P. \& Diop, M., Application of daily rainfall principal component analysis to the assessment of the rainy season characteristics in Senegal. Climate Research, 23, pp. 159-169, 2003. doi: http://dx.doi.org/10.3354/cr023159

[14] Valero, F., Martın, M.L., Sotillo, M.G., Morata A. \& Luna, M.Y., Characterization of the autumn Iberian precipitation from long-term datasets: comparison between observed and hindcasted data. International Journal of Climatology, 29, pp. 527-541, 2009. doi: http://dx.doi. org/10.1002/joc. 1726

[15] Sivapragasam, C., Liong, S.Y. \& Pasha, M.F.K., Rainfall and runoff forecasting with SSASVM approach. Journal of Hydroinformatics, 3(7), pp. 141-152, 2001.

[16] Irving, D.B., Whetton, P. \& Moise, A.F., Climate projections for Australia: a first glance at CMIP5. Australian Meteorological and Oceanographic Journal, 62, pp. 211-225, 2012.

[17] Intergovernmental Panel on Climate Change, Climate Change 2014: Impacts, Adaptation and Vulnerability, Working Group II Report to be released in Yokohama, Japan, March 2014. doi: http://dx.doi.org/10.1017/cbo9781107415379

[18] Pennell, C. \& Reichler, T., On the effective number of climate models. Journal of Climate, 24(9), pp. 2358-2367, 2011. doi: http://dx.doi.org/10.1175/2010jcli3814.1

[19] Raisanen, J. \& Ylhaisi, J.S., Can model weighting improve probabilistic projections of climate change? Climate Dynamics, 39(7-8), 2012. doi: http://dx.doi.org/10.1007/s00382-011-1217-8

[20] Raisanen, J., Ruokolainen, L. \& Ylhaisi, J., Weighting of model results for improving best estimates of climate change. Climate Dynamics, 35, pp. 407-422, 2010. doi: http://dx.doi. org/10.1007/s00382-009-0659-8 
[21] Tebaldi, C. \& Knutti, R., The use of the multi-model ensemble in probabilistic climate projections. Philosophical Transactions of the Royal Society A-Mathematical Physical and Engineering Sciences, 365(1857), pp. 2053-2075, 2007. doi: http://dx.doi.org/10.1098/rsta.2007.2076

[22] Reichler, T. \& Kim, J., How well do coupled models simulate today's climate? Bulletin of American Meteorological Society, 89, pp. 303-311, 2008. doi: http://dx.doi.org/10.1175/ bams-89-3-303

[23] Jun, M., Knutti, R. \& Nychka, D.W., Spatial analysis to quantify numerical model bias and dependence: how many climate models are there? Journal of the American Statistical Association, 103, pp. 934-947, 2008. doi: http://dx.doi.org/10.1198/016214507000001265

[24] Pincus, R., Batstone, C.P., Hofmann, R.J.P., Taylor, K.E. \& Gleckler, P.J., Evaluating the present-day simulation of clouds, precipitation, and radiation in climate models. Journal of Geophysical Research Letters, 113, D14209, 2008. doi: http://dx.doi.org/10.1029/2007jd009334

[25] Klingaman, N., Rainfall in Queensland, Part 5: Projected changes in Queensland rainfall under double-CO2 conditions in the HiGEM model, Queensland Climate Change Centre of Excellence, Queensland government, August 2012.

[26] Drosdowsky, W. \& Chambers, L.E., Near-global sea surface temperature anomalies as predictors of Australian seasonal rainfall. Journal of Climate, 14, pp. 1677-1687, 2001. doi: http:// dx.doi.org/10.1175/1520-0442(2001)014\%3C1677:nacngs\%3E2.0.co;2 